\title{
ETNOBOTANI ROTAN JERNANG (Calamus spp.) PADA MASYARAKAT SAROLANGUN, JAMBI
}

\author{
Ethnobotany of jernang rattan (Calamus spp.) by the community of Sarolangun, Jambi
}

\author{
Revis Asra ${ }^{1 *}$, Dyan Andryani ${ }^{1}$, Ade Adriadi ${ }^{1}$, Izu Andry Fijridiyanto ${ }^{2}$, Joko Ridho Witono ${ }^{2}$, Oliver Gailing ${ }^{3}$ \\ ${ }^{1}$ Program Studi Biologi, Fakultas Sains dan Teknologi, Universitas Jambi \\ Mendalo Darat, 36361, Jambi, Indonesia \\ 2 Pusat Penelitian Konservasi Tumbuhan dan Kebun Raya, Lembaga IImu Pengetahuan Indonesia (LIPI) \\ Ir. H. Juanda No.13 Bogor, Jawa Barat, Indonesia \\ ${ }^{3}$ Büsgen-Institute Forest Genetics and Forest Tree Breeding, \\ Georg-August-Universität Göttingen, Germany
}

\section{Informasi Artikel}

Diterima/Received : 27 April 2021

Disetujui/Accepted : 28 Agustus 2021

Diterbitkan/Published : 31 Agustus 2021

*Koresponden E-mail :

revisasra@unja.ac.id

DOI: https://doi.org/10.14203/bkr.v24i2.724

\section{Cara mengutip}

Asra R, Andryani D, Adriadi A, Fijridiyanto IA, Witono JR, Gailing O. 2021. Etnobotani rotan jernang (Calamus spp.) pada masyarakat

Sarolangun, Jambi. Buletin Kebun Raya 24(2): 76-84.

DOI: https://doi.org/10.14203/bkr.v24i2.724

\section{Kontributor}

\section{Kontributor Utama/Main author:}

Revis Asra

Dyan Andryani

Ade Adriadi

Izu Andry Fijridiyanto

Joko Ridho Witono

Oliver Gailing

Kontributor Anggota/Author member:

Keywords: cultivation, Calamus, ethnobotany, jernang

Kata Kunci: budidaya, Calamus, etnobotani, jernang

\begin{abstract}
Jernang rattan (Calamus spp.) is an essential source of income for the people of Seko Besar and Taman Bandung Villages, who live near natural forests in Sarolangun Regency, Jambi. The skin of jernang fruit contains red resin, which has high economic value as a raw material for medicines and natural dyes. This study aimed to explore the biodiversity of the species of jernang in these regions, examine the differences of each species, uses, traditional processing of jernang resin, conservation efforts, use and cultural values. The method used was direct interviews based on specific criteria (snowball sampling) to 40 respondents, participatory observation, and documentation. Use values were calculated using Use Value (UV), and cultural values were calculated using the Index of Cultural Significance (ICS). The research result showed four species of jernang in Seko Besar and Taman Bandung Villages, namely Calamus draco Willd. (jernang rambai), C. micracanthus Griff. (jernang kelamuai), C. maculatus (J.Dransf.) W.J.Baker (jernang bengkarung), and C. didymophyllus (Becc.) Ridl. (jernang burung). The jernang was traditionally used as medicine for several diseases and handicrafts. The community carried out conservation and cultivation by planting jernang in rubber gardens around the house yard and harvesting the fruit without damaging the parent plants. The highest UV value was 1 in $C$. draco and $C$. micracanthus and the lowest was 0.85 in $C$. maculatus. The ICS value of $C$. draco and $C$. micracanthus were 18 while, $C$. didymophyllus and C. maculatus were 2.5 .
\end{abstract}

\footnotetext{
Abstrak

Rotan jernang (Calamus spp.) merupakan salah satu sumber penghasilan yang penting bagi masyarakat Desa Seko Besar dan Taman Bandung yang bermukim di dekat hutan alam di Kabupaten Sarolangun, Jambi. Kulit buah jernang mengandung resin merah yang memiliki nilai ekonomi tinggi karena bermanfaat sebagai bahan baku obat dan pewarna alami. Penelitian ini bertujuan mengeksplorasi jenis-jenis jernang di daerah tersebut, mengkaji perbedaan dari setiap jenis, mengetahui pemanfaatan, cara pengolahan resin jernang secara tradisional, upaya pelestarian dan mengetahui nilai guna dan nilai budaya. Metode yang digunakan adalah wawancara langsung berdasarkan kriteria tertentu (snowball sampling) terhadap 40 responden, observasi partisipatif, dan dokumentasi. Nilai guna dihitung dengan menggunakan Use Value (UV) dan nilai nilai budaya dihitung dengan menggunakan Index of Cultural Significance (ICS). Berdasarkan hasil penelitian ditemukan empat jenis-jenis jernang di Desa Seko Besar dan Taman Bandung yaitu Calamus draco Willd. (jernang rambai), C. micracanthus Griff. (jernang kelamuai), C. maculatus (J.Dransf.) W.J.Baker (jernang bengkarung), dan C. didymophyllus (Becc.) Ridl. (jernang burung). Pemanfaatan jernang secara tradisional oleh masyarakat yaitu sebagai obat untuk menyembuhkan beberapa penyakit dan bahan kerajinan tangan. Upaya pelestarian dan budidaya yang oleh masyarakat yaitu dengan menanam jernang pada kebun karet di sekitar pekarangan rumah dan pemanenan buah yang tidak merusak tanaman induknya. Nilai UV tertinggi terdapat pada jenis $C$. draco dan $C$. micracanthus yaitu 1,00 dan terendah $C$. maculatus yaitu 0,85 . Nilai ICS rotan jernang $C$. draco dan $C$. micracanthus yaitu 18 , sedangkan $C$. didymophyllus dan $C$. maculatus yaitu 2,5 .
} 


\section{PENDAHULUAN}

Etnobotani mencakup pemanfaatan tumbuhan serta interaksinya dengan manusia dan termasuk upaya pelestarian terhadap tumbuhan tersebut. Pemanfaatan tumbuhan meliputi hampir seluruh aspek kebutuhan hidup masyarakat seperti pangan, obat, bangunan, hiasan, pakan dan kebutuhan hidup lainnya (Arizona 2011). Sumber daya hayati yang banyak dimanfaatkan oleh masyarakat Indonesia sejak dahulu adalah Hasil Hutan Bukan Kayu (HHBK) (Sakinah et al. 2019). Salah satu HHBK yang bernilai ekonomis tinggi dan masih dimanfaatkan oleh masyarakat saat ini adalah rotan jernang (Calamus spp.).

Jernang merupakan sebutan untuk jenis-jenis rotan yang dapat mengeluarkan resin yang berwarna merah pada bagian kulit buahnya, seperti yang ditemukan pada Calamus draco Willd. Distribusi rotan jernang terbatas di bagian barat Asia Tenggara yaitu Indonesia, Malaysia, dan Thailand. Di Indonesia, jernang ditemukan di Kalimantan dan Sumatra (Rustiami et al. 2004). Jernang di Provinsi Jambi terdapat di Kabupaten Tebo, Bungo, Sarolangun, Merangin, kawasan Taman Nasional Bukit Dua Belas, dan kawasan hutan Kapas (Sahwalita \& Kurniawan 2013). Menurut Asra \& Farid (2017), di Kabupaten Sarolangun khususnya di Kecamatan Pauh merupakan salah satu daerah yang banyak ditemukan jernang. Dua desa di kecamatan tersebut, yaitu Desa Seko Besar dan Taman Bandung berbatasan langsung dengan hutan alam, sehingga masih banyak ditemukan berbagai jenis jernang.

Istilah jernang sering dianalogikan sebagai komponen resin hasil ekstraksi buah rotan jernang (Calamus spp.), resin yang dihasilkan berwarna merah yang terdapat pada permukaan kulit dan daging buahnya (Asra 2014). Menurut Gupta et al. (2008), resin C. draco mengandung dracorhodin, dracorubin, dracoalban, dracoresene, dracoresinotannol, dracooxepine dan dracoflavan. Dracorhodin merupakan senyawa utama pada resin jernang (Waluyo \& Wibowo 2018). Resin ini berfungsi sebagai bahan baku untuk obat anti tumor, antivirus, antimikroba, memiliki aktivitas sitotoksik, dan melancarkan sirkulasi darah serta sebagai bahan baku kosmetik (Rao et al. 1982; Edward et al. 2001; Gupta et al. 2008; Sulasmi et al. 2012; Waluyo \& Pasaribu 2015; JuraMorawiec \& Tulik 2016).

Di Desa Seko Besar dan Taman Bandung, jernang merupakan salah satu sumber penghasilan secara turun temurun. Namun saat ini keberadaan jernang semakin menurun dan langka. Menurut Balai Litbang LHK Palembang (2016), jernang sudah dikategorikan langka. Hal ini disebabkan berkurangnya luasan hutan, rusaknya habitat jernang dan sistem pemanenan yang tidak lestari. Menurunnya populasi jernang di hutan alam menyebabkan masyarakat mulai kesulitan dalam mendapatkan jernang, sehingga pendapatan masyarakat dari jernang menjadi turun.

Berdasarkan uraian tersebut maka Penelitian ini bertujuan mengeksplorasi jenis-jenis jernang di Desa Seko Besar dan Taman Bandung Kabupaten Sarolangun Jambi, mengkaji perbedaan dari setiap jenis, mengetahui pemanfaatan, cara pengolahan resin jernang secara tradisional, upaya pelestarian dan mengetahui nilai guna dan nilai budaya.

\section{BAHAN DAN METODE}

\section{Lokasi dan waktu penelitian}

Penelitian ini dilakukan di Desa Seko Besar dan Taman Bandung, Kecamatan Pauh, Kabupaten Sarolangun, Provinsi Jambi pada bulan September 2019 sampai Maret 2020.

\section{Teknik Pemilihan Responden}

Pemilihan responden dilakukan dengan menggunakan metode purposive sampling yaitu dengan memilih masyarakat yang pernah mencari atau mengambil jernang di hutan, dan masyarakat yang telah melakukan budidaya jernang di sekitar pekarangan rumah dan di kebun karet milik masyarakat. Responden yang mengetahui rotan jernang di Desa Seko Besar dan Taman Bandung adalah masyarakat suku Melayu dan berusia di atas 30 tahun.

\section{Pengumpulan Data}

Pengumpulan data dilakukan dengan wawancara semi terstruktur dan mendalam (in-depth interview) serta observasi partisipatif (snowball method). Wawancara dilakukan di Desa Seko Besar dan Taman Bandung terhadap 40 orang responden, yang terdiri atas empat orang responden kunci (orang yang paling memahami tentang rotan jernang) dan 36 orang responden umum. Wawancara dengan para responden dilakukan pada saat mereka memiliki waktu luang.

Setiap kegiatan para responden yang berkaitan dengan pengetahuan lokal tentang rotan jernang, di antaranya pencarian jernang di hutan, melihat perbedaan dari setiap jenis rotan jernang, dan pemanenan buah rotan jernang yang dibudidayakan oleh masyarakat selalu diikuti. Sampel jernang diambil dan diidentifikasi berdasarkan herbarium yang ada di Program Studi Biologi, Fakultas Sains dan Teknologi Universitas Jambi.

Peralatan yang digunakan dalam pemanenan jernang oleh pencari jernang dengan memanfaatkan bahan-bahan yang ada di alam, seperti kayu pengait, rotan sebagai pengikat, kayu penjuluk, dan kunju (keranjang rotan). Kegiatan lain yang diamati yaitu cara pengolahan buah rotan jernang, melihat dan mengetahui fungsi dari 
alat panen dan pengolahan yang akan dipakai, dan menyiapkan alat panen serta alat-alat yang diperlukan untuk pengolahan jernang.

\section{Analisis Data}

Analisis data dilakukan secara kualitatif dan kuantitatif. Analisis kualitatif meliputi data tentang pengetahuan lokal masyarakat tentang rotan jernang, sedangkan analisis kuantitatif berupa indeks Use Value (UV) dan Index of Culture Significance (ICS) (Turner 1988; Phillips \& Gentry 1993) dengan persamaan sebagai berikut:

$$
\mathrm{ICS}=\sum_{k=1}^{n}(\mathrm{q} \times \mathrm{i} \times \mathrm{e}) \mathrm{ni}
$$

Keterangan:

ICS = Index of Cultural Significance (persamaan jumlah nilai suatu jenis tumbuhan dari kegunaan 1 hingga ke $n$, di mana $n$ menunjukkan kegunaan terakhir dari suatu jenis tumbuhan)

$\mathrm{q}=$ nilai kualitas (quality value)

$\mathrm{i} \quad=$ nilai intensitas (intensity value)

$\mathrm{e} \quad=$ nilai eksklusivitas (exclusive value)

$\mathrm{ni}=$ nilai kegunaan tumbuhan

$$
U V=\frac{\sum \mathrm{UVis}}{\mathrm{i}_{s}}
$$

Keterangan :

UV = nilai guna jenis secara keseluruhan

UVis = nilai jenis s yang di determinasi oleh informan $\mathrm{i}$

$\mathrm{i}_{\mathrm{s}} \quad=$ jumlah informan yang diwawancarai untuk jenis

\section{HASIL DAN PEMBAHASAN}

\section{Keanekaragaman jenis jernang}

Menurut Rustiami et al. (2004), di Sumatra ditemukan enam jenis rotan jernang yang dapat menghasilkan resin yang berwarna merah yaitu Daemonorops siberutensis Rustiami, D. acehensis Rustiami, D. brachystachys Furtado, D. draconcella Becc., $D$. dransfieldii Rustiami dan D. draco Willd. Saat ini, seluruh jenis dari marga Daemonorops merupakan sinonim dari marga Calamus (POWO 2021) Purwanto et al. (2005) menyatakan terdapat 12 jenis rotan jernang di Indonesia yang dapat menghasilkan resin, yaitu $C$. acehensis (Rustami) W.J.Baker, C. dracuncula Ridl., C. brachypodus W.J.Baker, C. didymophyllus (Becc.) Ridl., C. draco Willd., C. micracanthus Griff., $C$. johndransfieldii W.J.Baker, $C$. maculatus (J.Dransf.) W.J.Baker, C. ruber Reinw. ex Mart., C. siberutensis (Rustiami) W.J. Baker, C. uschdraweitiana (Burret) W.J.Baker dan C. sekundurensis (Rustiami \& Zumaidar) W.J.Baker.

Berdasarkan hasil observasi dan wawancara terhadap responden di Desa Seko Besar dan Taman Bandung diketahui empat jenis rotan jernang (Tabel 1).
Tabel 1. Jenis-jenis rotan jernang yang terdapat di Desa Seko Besar dan Taman Bandung

\begin{tabular}{cllcc}
\hline No & $\begin{array}{c}\text { Nama } \\
\text { daerah }\end{array}$ & Nama ilmiah & $\begin{array}{c}\text { Seko } \\
\text { Besar }\end{array}$ & $\begin{array}{c}\text { Taman } \\
\text { Bandung }\end{array}$ \\
\hline 1. & $\begin{array}{l}\text { Jernang } \\
\text { rambai }\end{array}$ & $\begin{array}{l}\text { Calamus } \\
\text { draco Willd. }\end{array}$ & $\mathrm{V}$ & $\mathrm{V}$ \\
2. & $\begin{array}{l}\text { Jernang } \\
\text { bengkarung }\end{array}$ & $\begin{array}{l}\text { C. maculatus } \\
\text { (J.Dransf.) } \\
\text { W.J.Baker }\end{array}$ & $\mathrm{V}$ & $\mathrm{V}$ \\
3. & Jernang & $\begin{array}{l}\text { C. } \\
\text { didymophyllus } \\
\text { burung }\end{array}$ & $\mathrm{V}$ & $\mathrm{V}$ \\
& $\begin{array}{l}\text { (Becc.) Ridl. } \\
\text { C. } \\
\text { micracanthus } \\
\text { kernang }\end{array}$ & $\mathrm{V}$ & $\mathrm{V}$ \\
& & & \\
\hline
\end{tabular}

\section{Nilai guna dan manfaat jernang}

a. Manfaat ekonomi

Rotan jernang memiliki manfaat ekonomi yang penting bagi masyarakat pribumi, khususnya penduduk asli bersuku Melayu. Rotan jernang juga dapat dimanfaatkan secara tradisional sebagai obat dan kerajinan tangan. Bagian utama rotan jernang yang dimanfaatkan adalah buah dan batangnya (Tabel 2). Pengetahuan dan pemanfaatan rotan jernang diwariskan secara turun temurun dari nenek moyang terdahulu. Pada umumnya masyarakat Desa Seko Besar dan Taman Bandung mengetahui cara membedakan berbagai jenis jernang berdasarkan bentuk daun, batang, dan buahnya.

Manfaat ekonomi rotan jernang yang diperoleh masyarakat Desa Seko Besar dan Taman Bandung adalah hasil penjualan langsung resin/getah jernang/buah jernang kepada pengumpul lokal (toke). Harga resin jernang tersebut berkisar antara Rp. 1.000.000,- - Rp. 3.000.000,- per kg, tergantung pasaran dan tingkat kemurnian resinnya. Di samping dijual langsung, resin jernang juga dimanfaatkan dalam kehidupan mereka sehari-hari, seperti untuk obat luka, pilis bagi ibu-ibu yang baru melahirkan, pewarna berbagai peralatan, seperti keranjang rotan, tikar pandan, dan topi. Tujuan pemberian warna pada berbagai peralatan adalah supaya peralatan tersebut lebih tahan lama (Tabel 2).

Jernang termasuk tumbuhan berumah dua dan yang menghasilkan buah hanyalah jernang betina. Walaupun jernang jantan tidak menghasilkan buah, namun masih memiliki nilai manfaat. Batang jernang jantan yang sudah tua dan panjang dapat digunakan untuk membuat kaki keranjang rotan (kaki kunju). Nilai jual keranjang rotan yang tidak diwarnai dengan resin jernang biasanya lebih murah dibandingkan dengan keranjang rotan yang diwarnai. 
Tabel 2. Pemanfaatan rotan jernang oleh masyarakat Desa Seko Besar dan Taman Bandung

\begin{tabular}{|c|c|c|c|c|}
\hline No & Pemanfaatan & $\begin{array}{l}\text { Bagian yang } \\
\text { dimanfaatkan }\end{array}$ & $\begin{array}{l}\text { Jenis jernang } \\
\text { yang digunakan }\end{array}$ & Cara pengolahan \\
\hline 1. & $\begin{array}{l}\text { Sumber } \\
\text { ekonomi }\end{array}$ & Buah & $\begin{array}{l}\text { C. draco } \\
\text { C. micracanthus } \\
\text { C. didymophyllus } \\
\text { C. maculatus }\end{array}$ & $\begin{array}{l}\text { Buah jernang yang tua diekstraksi dan menghasilkan resin, } \\
\text { kemudian dipadatkan dan siap dijual. Resin jernang dijual } \\
\text { kepada toke jernang. }\end{array}$ \\
\hline 2. & Obat luka & Getah (resin) & $\begin{array}{l}\text { C. draco } \\
\text { C. micracanthus }\end{array}$ & $\begin{array}{l}\text { Resin jernang yang padat digiling hingga halus, kemudian } \\
\text { ditaburkan ke luka. }\end{array}$ \\
\hline 3. & Pilis & Getah (resin) & $\begin{array}{l}\text { C. draco } \\
\text { C. micracanthus }\end{array}$ & $\begin{array}{l}\text { Resin dihaluskan, dibasahi dengan air atau spiritus dan } \\
\text { selanjutnya dioleskan ke kening ibu-ibu yang baru selesai } \\
\text { melahirkan. }\end{array}$ \\
\hline 4. & Pewarna & Getah (resin) & $\begin{array}{l}\text { C. draco } \\
\text { C. micracanthus }\end{array}$ & $\begin{array}{l}\text { Buah diekstraksi dan menghasilkan resin, kemudian } \\
\text { dicampur dengan spiritus, dan dicat ke kerajinan tangan, } \\
\text { seperti tudung/topi, tikar pandan dan keranjang rotan. }\end{array}$ \\
\hline 5. & Kaki kunju & Batang & $\begin{array}{l}\text { C. draco } \\
\text { C. micracanthus } \\
\text { C. didymophyllus } \\
\text { C. maculatus }\end{array}$ & $\begin{array}{l}\text { Batang dibersihkan dari duri dan kulit luarnya, kemudian } \\
\text { dikeringkan. }\end{array}$ \\
\hline
\end{tabular}

b. Nilai ekologi

Jernang membutuhkan tegakan pohon sebagai tempat merambat. Sebagian besar masyarakat Desa Seko Besar dan Taman Bandung merupakan petani karet, sehingga integrasi budidaya jernang di kebun karet merupakan bentuk integrasi yang tepat. Batang jernang tidak berukuran besar (lebih kecil dari batang rotan manau), sehingga tidak akan merobohkan batang karet meskipun digunakan sebagai penyangga. Selain itu juga ditemukan jernang di hutan sekitar kedua desa tersebut, di mana pohon-pohon yang ada di hutan tersebut berfungsi sebagai tegakannya. Pohon yang berfungsi sebagai tegakan tidak boleh ditebang, sehingga keberadaan pohon-pohon di hutan tetap dijaga oleh masyarakat di kedua desa tersebut.

c. Nilai sosial budaya

Budaya menggunakan resin sebagai pilis (ditempelkan di kening) bagi ibu-ibu yang baru melahirkan telah dilakukan sejak dahulu oleh masyarakat Desa Seko Besar dan Taman Bandung. Kebiasaan ini dipercaya untuk menghindari sakit kepala di kemudian hari. Pada umumnya jernang yang digunakan sebagai obat oleh penduduk desa setempat, dan tidak ada transaksi jual belinya. Penduduk yang membutuhkan hanya meminta kepada orang yang memiliki pohon jernang. Hal tersebut menggambarkan masih kentalnya nilai sosial budaya yang berlaku di masyarakat Desa Seko Besar dan Taman Bandung.

\section{Kegiatan ekstraksi kering buah rotan jernang}

Pengolahan jernang oleh masyarakat di Desa Seko Besar dan Taman Bandung dilakukan dengan cara ekstraksi kering, karena tanpa menggunakan pelarut atau air. Jernang yang baru selesai dipanen, dikering anginkan terlebih dahulu agar buah rontok dan mudah untuk dipetik dari tangkainya. Buah rotan jernang dimasukkan ke dalam ambung (keranjang rotan) (Gambar 1a), kemudian ditumbuk dan diguncang di atas kayu penyangga (Gambar 1b) secara perlahan menggunakan kayu sentubung yang dibuat bercabang 2-5, seperti kaki ayam (Gambar 1c). Selanjutnya resin akan jatuh dari celah-celah ambung yang ditampung menggunakan karung (Gambar 1d dan 2a). Resin yang dihasilkan masih terdapat serpihan kulit buah rotan jernang (Gambar 2b), dan harus dibersihkan terlebih dahulu, baru kemudian dimasukkan ke dalam plastik (Gambar 2c) yang akan memadat dalam waktu \pm 8 jam (Gambar 2d). Teknik pengguncangan atau ekstraksi dilakukan dengan cara memasukkan buah rotan jernang ke dalam ambung, kemudian menggoyang ambung secara perlahan sambil menumbuk buah rotan dengan kayu sentubung dengan hati-hati agar buah jernang tidak hancur. Resin yang dihasilkan dengan cara ekstraksi ini sedikit tercampur dengan sisik kulit buah rotan jernang. 


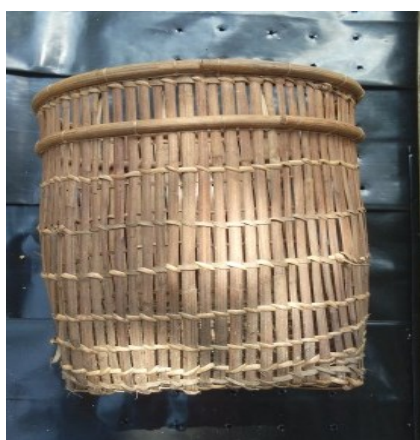

a

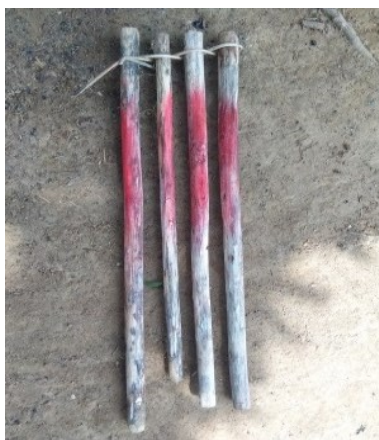

b

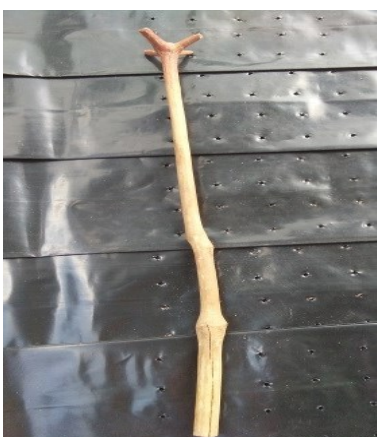

C

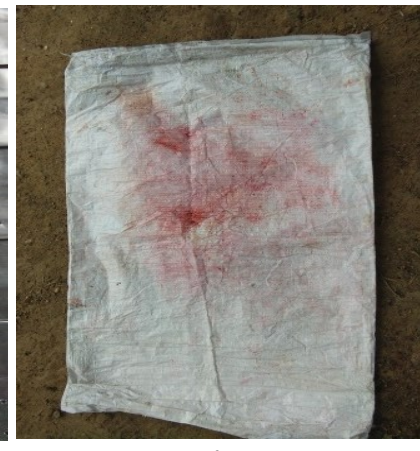

d

Gambar 1. Alat ekstraksi jernang. (a) ambung, (b) kayu penyangga, (c) kayu sentubung, (d) karung

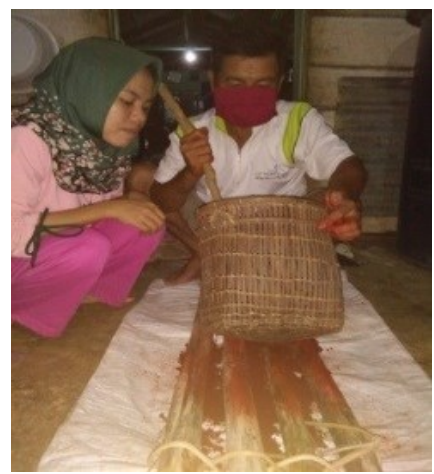

a

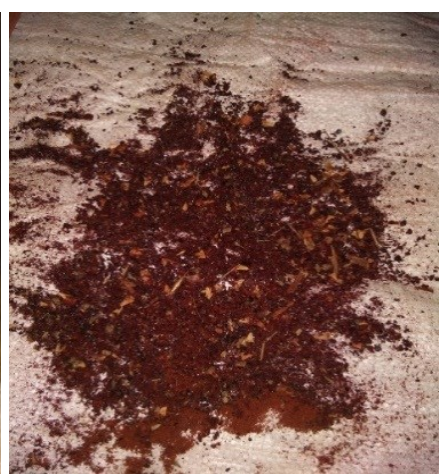

b

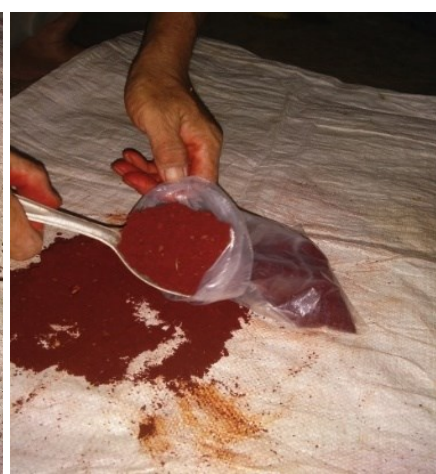

C

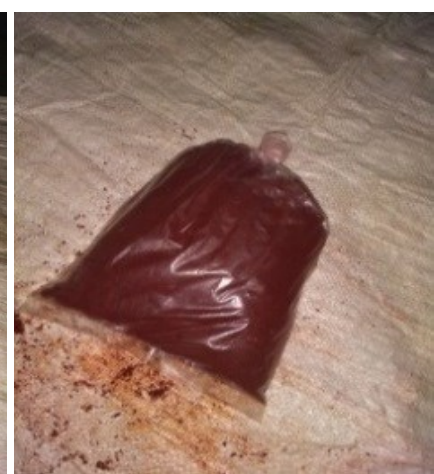

d

Gambar 2. Proses ekstraksi kering. (a) proses pengguncangan, (b) resin hasil ekstraksi, (c) proses pemasukan resin ke dalam plastik, (d) resin hasil ekstraksi yang telah dimasukkan ke dalam plastik

\section{Prospek pengembangan rotan jernang}

Rotan jernang merupakan salah satu tanaman budidaya yang memiliki nilai sosial budaya bagi masyarakat lokal yang dapat dikembangkan sebagai sumber penghasilan bagi keluarga. Selain itu, rotan jernang juga digunakan sebagai bahan baku industri, obat, dan pewarna alami yang dapat dikembangkan sebagai produk industri farmasi, bahan baku obat herbal dan industri lainnya. Permintaan jernang semakin meningkat setiap tahunnya. Mengingat populasi jernang di hutan alam yang semakin menurun, maka masyarakat Desa Seko Besar dan Taman Bandung mulai membudidayakannya dengan pola tumpang sari. Budidaya rotan jernang di kedua desa tersebut diharapkan menjadi salah satu upaya untuk menjamin kelestarian rotan jernang yang keberadaannya sudah semakin terbatas, dan diharapkan dapat berperan untuk meningkatkan pendapatan masyarakat.

\section{Upaya pelestarian rotan jernang}

Berdasarkan hasil survei, masyarakat Desa Seko Besar dan Taman Bandung telah melakukan pembudidayaan rotan jernang melalui biji yang sudah tua. Budidaya rotan jernang di kedua desa tersebut dilakukan dengan cara menanam jernang pada kebun karet di sekitar pekarangan rumah. Pohon karet digunakan sebagai penyangga atau sebagai tempat untuk rambatan rotan jernang.

Jumlah bibit jernang yang ditanam di kebun karet tergantung dari ketersediaan bibit yang dimiliki.
Diperkirakan jumlah jernang yang ditanam dengan pola tumpang sari sebanyak \pm 90 rumpun per ha. Jernang ditanam di dekat pohon karet dengan jarak $\pm 1 \mathrm{~m}$, sedangkan jarak jernang satu dan lainnya $\pm 10 \mathrm{~m}$. Penanaman dengan pola tumpang sari dapat memberikan dua manfaat sekaligus bagi masyarakat, yaitu berupa hasil produksi resin jernang dan hasil produksi getah karet. Pertumbuhan jernang dapat dimonitor secara reguler oleh masyarakat sambil melakukan penyadapan getah pada pohon karet.

Tahapan dari pembudidayaan jernang yang dilakukan oleh masyarakat meliputi:

a. Pemilihan benih

Benih yang digunakan yaitu biji dari buah jernang yang sudah tua atau masak dengan ciri-ciri sebagai berikut: berukuran sebesar jempol orang dewasa, daging buahnya sudah kering, dan memiliki warna yang kemerahan sampai kehitaman. Buah yang masak dibersihkan terlebih dahulu dari resin (getah) yang terdapat di permukaan kulit buahnya. Selanjutnya daging buah dibersihkan agar biji dapat berkecambah lebih cepat.

b. Penyemaian

Metode yang digunakan masyarakat untuk mempercepat perkecambahan biji adalah sebagai berikut: biji dijemur sekitar 10 menit, selanjutnya direndam dengan air kelapa selama 24 jam, dan setiap 12 jam air kelapa diganti. Selanjutnya biji diambil dan dibersihkan, lalu dijemur kembali selama 10 menit. Biji 
jernang dimasukkan ke dalam toples atau plastik bening agar udara tidak dapat masuk. Biji akan berkecambah 21-26 hari kemudian. Bibit dipindahkan ke dalam polibag yang berisi campuran tanah hitam dan serbuk gergaji. Selanjutnya bibit diletakkan di tempat yang teduh dan disiram satu kali sehari.

c. Penanaman jernang

Penanaman rotan jernang dilakukan pada saat bibit berumur \pm 2 tahun. Rotan jernang mulai masuk fase generatif (berbuah) setelah berumur 5-7 tahun. Menurut masyarakat setempat, ada beberapa kendala dalam budidaya rotan jernang seperti keterbatasan buah/biji jernang yang tua dan lamanya perkecambahan.

d. Pemanenan jernang

Pemanenan buah rotan jernang dilakukan oleh masyarakat dengan cara memanjat pohon yang terdapat di sekitar tempat tumbuhnya (Gambar 3). Hal ini disebabkan karena batang rotan jernang berduri dan berukuran kecil (diameter sekitar $2 \mathrm{~cm}$ ), sehingga tidak mungkin dipanjat. Buah rotan jernang kemudian dikait dengan alat yang sederhana yaitu penjuluk (kayu kecil yang diberi pengait). Selanjutnya buah rotan jernang dibawa turun dan tidak boleh dijatuhkan dari atas pohon karena dapat menyebabkan getah yang terdapat di permukaan kulit akan rontok sebagian. Masyarakat memanen buah rotan jernang dua kali dalam setahun, yaitu panen pertama pada Juni yang disebut dengan panen besar (panen raya) dan panen kedua pada Desember yang disebut panen selang. Cara pemanenan jernang di lokasi penelitian sama dengan cara pemanenan jernang yang dilakukan di pedalaman Bireun (Aceh) yaitu dengan cara memanjat batang kayu tempat sandaran rotan jernang (Ridhwan et al. 2018).

Pemanenan jernang yang dilakukan oleh masyarakat di Desa Seko Besar dan Taman Bandung menggunakan alat tradisional yaitu penjuluk yang telah diikat pengait. Penggunaan alat tersebut diajarkan oleh nenek moyang terdahulu dan telah terbukti tidak merusak pertumbuhan rotan jernang. Ditinjau dari aspek ekologis, cara pemanenan ini dinilai lebih lestari, karena tidak merusak pohon induknya dan pohon tersebut tetap mampu berbuah.

\section{Use Value (UV) dan Index of Culture Significance (ICS) rotan jernang}

Berdasarkan hasil wawancara dengan responden, didapatkan nilai UV rotan jernang sebesar 0,85-1,00 dan nilai ICS sebesar 18 dan 2,5 (Tabel 3). Tingginya nilai UV pada jernang rambai dan jernang kelamuai dikarenakan banyak masyarakat Desa Seko Besar dan Taman Bandung yang membudidayakan kedua jenis jernang tersebut untuk kemudian dimanfaatkan sebagai salah satu penunjang perekonomian (dijual). Kedua jenis jernang tersebut merupakan jenis yang banyak menghasilkan resin dibandingkan dengan jenis jernang bengkarung dan jernang burung yang masuk kategori sangat rendah dalam menghasilkan resin.

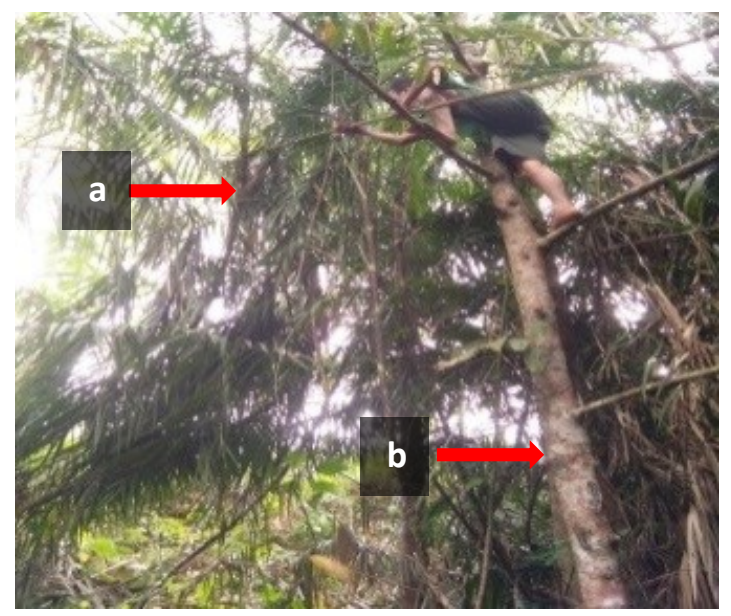

Gambar 3. Proses pemanenan buah rotan jernang. (a) rotan jernang, (b) pohon rambatan

Tabel 3. Use Value (UV) dan Index of Culture Significance (ICS) rotan jernang

\begin{tabular}{clcc}
\hline No & \multicolumn{1}{c}{ Jenis rotan jernang } & $\begin{array}{c}\text { Nilai } \\
\text { UV }\end{array}$ & $\begin{array}{c}\text { Nilai } \\
\text { ICS }\end{array}$ \\
\hline 1 & $\begin{array}{l}\text { Calamus draco Willd. } \\
\text { (Jernang rambai) }\end{array}$ & 1,00 & 18 \\
2 & $\begin{array}{l}\text { C. micracanthus Griff. (Jernang } \\
\text { kelamuai) }\end{array}$ & 1,00 & 18 \\
3 & $\begin{array}{l}\text { C. maculatus (J.Dransf.) W.J.Baker } \\
\text { (Jernang bengkarung) }\end{array}$ & 0,85 & 2,5 \\
4 & $\begin{array}{l}\text { C. didymophyllus (Becc.) Ridl. } \\
\text { (Jernang burung) }\end{array}$ & 0,90 & 2,5 \\
\hline
\end{tabular}

Perhitungan nilai ICS dilakukan untuk mengetahui seberapa penting rotan jernang bagi kehidupan masyarakat. Nilai ICS berhubungan dengan keberadaan dan jumlah tumbuhan tersebut di lingkungan sekitar. Menurut Silalahi et al. (2018), tumbuhan yang memiliki nilai ICS tinggi merupakan tumbuhan yang mudah ditemukan di lingkungan sekitar, sehingga mudah dikenali masyarakat.

Nilai ICS jernang rambai (C. draco) dan jernang kelamuai (C. micracanthus) sebesar18 (Tabel 4). Nilai ICS tersebut tergolong dalam kategori rendah. Hal ini berarti bahwa kedua jenis rotan tersebut tidak begitu banyak digunakan oleh masyarakat Desa Seko Besar dan Taman Bandung. Hal ini disebabkan keberadaan jernang di kedua desa tersebut sudah langka, sehingga menyebabkan pemanfaatannya juga semakin jarang bahkan tidak digunakan lagi.

Nilai ICS untuk jenis $C$. maculatus dan $C$. didymophyllus sebesar 2,5 (Tabel 4). Nilai tersebut tergolong dalam kategori sangat rendah. Berdasarkan hasil 
penelitian Munawaroh et al. (2020) di Kabupaten Tanjung Jabung, Jambi, beberapa jenis rotan seperti $C$. insignis, $C$. sabut, $C$. Javensis, dan C. laevigatus memiliki nilai ICS yang lebih besar yaitu masing-masing 41. Hal ini disebabkan karena ke empat jenis Calamus tersebut memiliki umbut yang digunakan untuk bahan makanan sebagai sayuran.

Tabel 4. Perhitungan nilai Index of Culture Significance (ICS) empat jenis jernang di Desa Seko Besar dan Taman Bandung

\begin{tabular}{|c|c|c|c|c|c|c|c|c|}
\hline \multirow{2}{*}{ No } & \multirow{2}{*}{ Jenis jernang } & \multirow{2}{*}{ Parameter } & \multicolumn{5}{|c|}{ Kegunaan } & \multirow{2}{*}{ ICS } \\
\hline & & & Obat luka & Pilis & Pewarna & Kaki kunju & Dijual & \\
\hline \multirow[t]{4}{*}{1} & Calamus didymophyllus (Becc.) & $q$ & & & & 3 & 2 & $1,5+1=2,5$ \\
\hline & Ridl. (Jernang Burung) & $\mathrm{i}$ & & & & 1 & 0,5 & \\
\hline & & $\mathrm{e}$ & & & & 0,5 & 1 & \\
\hline & & $q \times i \times e$ & - & - & - & 1,5 & 1 & \\
\hline \multirow[t]{4}{*}{2} & Calamus draco Willd. (Jernang & $q$ & 3 & 3 & 3 & 3 & 2 & $3+1,5+6+$ \\
\hline & Rambai) & $\mathrm{i}$ & 2 & 1 & 2 & 1 & 3 & $1,5+6=18$ \\
\hline & & $\mathrm{e}$ & 0,5 & 0,5 & 1 & 0,5 & 1 & \\
\hline & & $q \times i \times e$ & 3 & 1,5 & 6 & 1,5 & 6 & \\
\hline \multirow[t]{4}{*}{3} & Calamus maculatus (J.Dransf.) & $q$ & & & & 3 & 2 & $1,5+1=2,5$ \\
\hline & W.J.Baker (Jernang & $\mathrm{i}$ & & & & 1 & 0,5 & \\
\hline & Bengkarung) & $\mathrm{e}$ & & & & 0,5 & 1 & \\
\hline & & $q \times i \times e$ & - & - & - & 1,5 & 1 & \\
\hline \multirow[t]{4}{*}{4} & Calamus micracanthus Griff. & $q$ & 3 & 3 & 3 & 3 & 2 & $3+1,5+6+$ \\
\hline & (Jernang Kelamuai) & $\mathrm{i}$ & 2 & 1 & 2 & 1 & 3 & $1,5+6=18$ \\
\hline & & $\mathrm{e}$ & 0,5 & 0,5 & 1 & 0,5 & 1 & \\
\hline & & $q \times i \times e$ & 3 & 1,5 & 6 & 1,5 & 6 & \\
\hline
\end{tabular}

Keterangan:

$q=$ nilai kualitas: (nilai 5 = bahan makanan utama; 4 = bahan makanan tambahan; 3 = bahan obat tradisional; 2 = bahan ritual, mitos, rekreasi; $1=$ hanya diketahui kegunaannya saja)

$\mathrm{i}$ = nilai intensitas: (nilai 5 = sangat tinggi intensitas penggunaan; 4 = penggunaan moderat; $3=$ penggunaan sedang; 2 = penggunaan rendah; 1 = penggunaan sedikit)

e = nilai eksklusivitas: (Nilai 2 = paling disuka/pilihan utama; 1 = terdapat beberapa jenis yang jadi pilihan; 0,5 = bahan sekunder) (Turner 1988)

Menurut Turner (1988), suatu jenis tumbuhan akan memiliki nilai ICS tertinggi, jika tumbuhan tersebut digunakan sebagai bahan makan utama, dengan intensitas penggunaan yang tinggi dan paling disukai oleh suatu komunitas masyarakat untuk digunakan. Nilai ICS suatu tumbuhan akan semakin bertambah dengan banyaknya jumlah kegunaan tumbuhan tersebut oleh masyarakat. Masyarakat Desa Seko Besar dan Taman Bandung menggunakan empat jenis rotan jernang dalam kehidupan sehari-hari mereka. Nilai ICS ke empat jenis rotan jernang ini tidak terlalu tinggi, karena rotan-rotan tersebut tidak ada yang memiliki kegunaan sebagai bahan makanan. Meskipun demikian, jenis $C$. draco dan C. micracanthus memiliki nilai ICS yang lebih tinggi dibanding dua jenis jernang lainnya. Hal ini menunjukkan bahwa kedua jenis rotan jernang tersebut cukup penting secara budaya bagi masyarakat Desa Seko Besar dan Taman Bandung

Nilai ICS yang didapatkan dari keempat jenis jernang menunjukkan hasil yang rendah. Saat ini populasi jernang di Desa Seko Besar dan Taman Bandung juga rendah dan semakin menurun, maka perlu dilakukan penanganan khusus baik dalam aspek penelitian dan pengembangannya agar kelestarian dari jenis-jenis jernang tersebut dapat tetap terpelihara.

Upaya pelestarian yang dilakukan masyarakat dengan pola tumpang sari pada kebun karet di sekitar pekarangan rumah adalah salah satu cara untuk dapat menjaga kelestarian jernang. Menurut Silalahi et al. (2015), tumbuhan yang memiliki nilai ICS tinggi merupakan tumbuhan yang intensif dan eksklusif digunakan masyarakat, sehingga perlu dijaga kelestariannya. Tumbuhan eksklusif yang digunakan masyarakat kadangkadang tidak dapat digantikan dengan jenis tumbuhan lain dan memiliki nilai kultural. Sebagai contoh penggunaan Citrus hystix dalam sauna tradisional etnis Batak tidak dapat digantikan jenis lain karena menghasilkan aroma khas dan memberi efek relaksasi (Silalahi \& Nisyawati 2019).

\section{KESIMPULAN}

Ditemukan empat jenis rotan jernang di Desa Seko Besar dan Taman Bandung, Kabupaten Sarolangun, Provinsi Jambi, yaitu jernang rambai (Calamus draco), jernang kelamuai (C. micracanthus), jernang burung ( $C$. didymophyllus) dan jernang bengkarung (C. maculatus). Jernang dimanfaatkan sebagai obat luka, obat setelah melahirkan (pilis), bahan pewarna kerajinan dari daun pandan (tudung dan tikar pandan), dan keranjang rotan (kunju) oleh masyarakat. Cara pengolahan buah menjadi resin yang dilakukan oleh masyarakat yaitu dengan cara ekstraksi kering. Upaya pelestarian rotan jernang yang dilakukan masyarakat dengan pola tumpang sari pada 
kebun karet di sekitar pekarangan rumah adalah salah satu cara untuk dapat menjaga kelestarian jernang dan memberikan keuntungan baik nilai ekonomi, ekologi, dan sosial budaya.

\section{UCAPAN TERIMA KASIH}

Penulis mengucapkan terima kasih kepada ABS Fund CRC 990 yang telah mendanai penelitian ini. Ucapan terima kasih juga disampaikan kepada para responden dan Kepala Desa Seko Besar dan Taman Bandung, Kabupaten Sarolangun, Provinsi Jambi yang telah memfasilitasi dan mendukung penelitian ini.

\section{DAFTAR PUSTAKA}

Arizona C. 2011. Etnobotani dan potensi tumbuhan berguna di Taman Nasional Gunung Ciremai, Jawa Barat. Skripsi, Fakultas Kehutanan, Institut Pertanian Bogor. Bogor.

Asra R. 2014. Seleksi primer inter simple sequence repeats (ISSR) pada Calamus draco (Willd.) Blume (Arecaceae). Jurnal Penelitian Universitas Jambi Seri Sains 16 (1): 9-14.

Asra R, Farid F. 2017. Budidaya rotan jernang untuk petani karet di Pauh. Jurnal Karya Abdi Masyarakat 1(2): 80-84.

Balai Litbang LHK Palembang. 2016. Kembangkan rotan jernang di Jambi, peneliti BLI inisiasi pertemuan para pihak. https://www.bpkpalembang.org/information/litbangfocus/kembangkan-rotan-jernang-di-jambipeneliti-bli-inisiasi-pertemuan-para-pihak (diakses 28 Agustus 2021).

Edward HGM, De Oliveira LFC, Quye A. 2001. Raman spectroscopy of coloured resins used in antiquity: Dragon's blood and related substances. Spectrochimica Acta-Part A. Molecular and Biomolecular Spectroscopy 57(14): 2831-2842.

Gupta D, Bleakley B, Gupta RK. 2008. Dragons's blood: Botany, Chemistry and Therapeutic Uses. Journal of Ethnopharmacology 115: 361-380.

Jura-Morawieck J, Tulik M. 2016. Dragon's blood secretion and its ecological significance. Chemoecology 26: 101-105.

Munawaroh E, Isnaini $Y$, Ajiningrum PS, Susiarti $S$, Purwanto Y. 2020. Cultural significance analysis to support the valuation of non timber forest products of the Malay Community in Tanjung Jabung, Jambi, Sumatera. Journal of Tropical Ethnobiology 3(2): 149-174.
Phillips O, Gentry AH. 1993. The useful plants of Tambopata, Peru: Statistical hypotheses tests with a new quantitative technique. Economic Botany 47: 15-32.

POWO. 2021. Plants of the World Online http://www.plantsoftheworldonline.org/ Diakses 25 Agustus 2021.

Purwanto Y, Polosakan R, Susiarti S, Walujo EB. 2005. Ekstraktivisme jernang (Daemonorops spp.) dan kemungkinan pengembangannya: studi kasus di Jambi, Sumatera, Indonesia. Pusat Penelitian Biologi- LIPI, Bogor.

Rao GSR, Gehart MA, Lee RT, Mitscher LA, Drake S. 1982. Antimicrobial agents from higher plants: dragon's blood resin. Journal of Natural Products 45: 646648.

Ridhwan M, Andalia N, Armi, Yuhasriati. 2018. Etnobotani jernang masyarakat pedalaman Bireun. Biota 11 (2): 158-168.

Rustiami H, Setyowati FM, Kartawinata K. 2004. Taxonomy and uses of Calamus draco (Willd.) Blume. Journal of Tropical Ethnobiology 1(2): 65-75.

Sahwalita, Kurniawan A. 2013. Teknik budidaya jenis rotan penghasil jernang. Laporan Hasil Penelitian Balai Penelitian Kehutanan, Palembang.

Sakinah B, Afriyansyah, Akbarini C. 2019. Etnobotani rotan sebagai bahan kerajinan anyaman oleh masyarakat di Kabupaten Bangka Barat. Al-Kauniyah 12(1): 1824.

Silalahi M, Supriatna J, Walujo EB. 2015. Local knowledge of medicinal plants in sub-ethnic Batak Simalungun of North Sumatra, Indonesia. Biodiversitas 16(1): 44-54.

Silalahi M, Nisyawati, Waluyo BE, Mustaqim W. 2018. Etnomedisin tumbuhan obat oleh sub etnis Batak Phakpak di Desa Surung Mersada, Kabupaten Phakpak Bharat, Sumatera Utara. Jurnal IImu Dasar 19(2): 77-92.

Silalahi M, Nisyawati. 2019. An ethnobotanical study of traditional steam-bathing by the Batak people of North Sumatra, Indonesia. Pacific Conservation Biology 25(3): 266-282.

Sulasmi IS, Nisyawati, Purwanto Y, Fatimah S. 2012. Jernang rattan (Calamus draco) management by Anak Dalam Tribe in Jebak Village, Batanghari, Jambi Province. Biodiversitas 13(3): 151-160.

Turner NJ. 1988. The importance of a rose: Evaluating the cultural significance of plants in Thompson and Lillooet Interior Salish. American Anthropologist 90 (2): 272-290. 
Waluyo TK, Pasaribu G. 2015. aktivitas antijamur, antibakteri dan penyembuhan luka ekstrak resin jernang. Jurnal Penelitian Hasil Hutan 33(4): 377385.
Waluyo TK, Wibowo S. 2018. Dracorhodin: A potential marker compound for detecting the presence of dragon's blood resin from Daemonorops originated from Indonesia. Biodiversitas 19(5): 1665-1671. 